Research Article

\title{
Study on the Mechanical Properties of Chlorine Saline Soil under the Interaction of Multiple Factors
}

\author{
Anhua Xu, ${ }^{1}$ Pengcheng Wang $\mathbb{D}^{2},{ }^{2}$ and Jianhong Fang ${ }^{3}$ \\ ${ }^{1}$ Qinghai Communication Technical College, Xining, Qinghai 810003, China \\ ${ }^{2}$ School of Civil Engineering, Qinghai University, Xining, Qinghai 810016, China \\ ${ }^{3}$ Qinghai Research Institute of Transportation, Xining, Qinghai 810016, China \\ Correspondence should be addressed to Pengcheng Wang; wpc0423@qq.com
}

Received 4 December 2020; Revised 19 February 2021; Accepted 20 April 2021; Published 30 April 2021

Academic Editor: Jianguo Wang

Copyright ( $\odot 2021$ Anhua Xu et al. This is an open access article distributed under the Creative Commons Attribution License, which permits unrestricted use, distribution, and reproduction in any medium, provided the original work is properly cited.

The distribution of chlorine saline soils is extensive in Haixi region of Qinghai Province in Northwest China. Its natural and geographical conditions are unique, and the external environment varies greatly. To study the effects of variable external environment on the mechanical characteristics of chlorine saline soils, a number of unconsolidated undrained (UU) dynamic triaxial tests under different confining pressure, moisture content, and loading frequency were carried out. The dynamic stress-dynamic strain, failure strength, dynamic elastic modulus, and parameter of shear strength were analyzed. The triaxial test results demonstrated that the stress-strain curves of the soil were strain-hardening. The failure strength and dynamic elastic modulus increased with the increasing of confining pressure; the law with moisture content and loading frequency were inconsistent. The dynamic cohesion and dynamic friction angle increased with the increasing of loading frequency, but decreased with the increasing of moisture content. Besides, the significance analysis theory was used to analyze the effect degree of different factors. It found that the effects of confining pressure, loading frequency, and the interaction between confining pressure and frequency on mechanical characteristics were significant, but the moisture content had less effect.

\section{Introduction}

Saline soil is a special type of soil that distributes to various degrees in many countries and regions. Similarly, saline soil is also widely distributed in China which covers approximately a total area of 36.9 million ha, accounting for $4.88 \%$ of Chinese available land area [1]. Nearly $69.03 \%$ of saline soil is mainly distributed in Xinjiang, Shaanxi, Ningxia, Inner Mongolia, Gansu, and Qinghai. The saline soil in Qinghai is mainly distributed in the west of the extremely arid Qaidam Basin, the mid-lower reaches of the Huangshui River Basin to the east of Xining, and the Pingchuan Plain area [2].

In recent years, many studies have been performed to investigate the engineering characteristics of saline soil. The shear strength of saline soil increases with increasing salt content due to the presence of salt crystals in soil $[3,4]$. Fang et al. [5] established a formula to describe salt expansion in soil containing sodium chloride and sodium sulfate through a combination of theory, salt swelling, and microscopic test. Zhang et al. [6] found that the shear stress-strain curve of the soil with high salinity showed stronger expansion and strain-softening behaviour due to an obvious change of temperature. Bing et al. [7] conducted a study on the influence of freeze-thaw cycles on the physical and mechanical properties of saline soil and showed that the samples had plastic failure after freeze-thaw cycles. Han et al. [8] studied the influence of the freeze-thaw cycle on the shear strength of saline soil in cold regions by triaxial compression test and proposed a reliable mathematical equation to describe the effect of interaction between freeze-thaw cycle and salt content on the maximum shear strength. Although the chloride salt does not chemically react with lime, its presence would increase the number of coarse particles in the soil and reduced the total surface area of the soil [9]. Liu et al. [10] demonstrated that the addition of lime in carbonate soil 
would result in a strong exchange between anion and cation, and the structure of soil particles and pores would change. The unconfined compressive strength increased with the increase of lime content. Zhang et al. [11] performed a mass of unconsolidated undrained triaxial tests that indicated that the shear strength of saline soil decreased with increasing salt content, and the sustaining deterioration of the strength was due to the freeze-thaw cycle destroying the soil grain structure through microscopic analysis. Some studies have shown that the incorporation of fly ash and other materials would have a certain effect on the strength characteristics of saline soil [12, 13]. Lai et al. [14] and Lai et al. [15] studied, respectively, the effect of cooling rate on salt crystallization and crystallization deformation of saline soil under freezing and thawing, which would not only describe the effect of cooling rate on initial crystallization and expansion of salt, but also propose a dynamic model considering nucleation, molecular diffusion, and crystal growth. Zhang et al. [16] demonstrated that adding slaked lime and other materials could not only effectively reduce the amount of salt expansion, but also reduced the sensitivity of salt expansion, and the feasibility and rationality of improving coarse sulfate saline soil with inorganic binder were clarified. Al-Amoudi et al. [17] found the reason why the arid saline soil had stronger collapsibility, which was that the soluble salt in the soil was dissolved. Mishra et al. [18] analyzed the influence of salinity on soil shrinkage characteristic curve. The dynamic strength criterion of frozen sulfate silty clay under cyclic loading was proposed, and the method for determining the dynamic strength parameter was given by Zhao et al. [19]. The effects of temperature, loading frequency, and other factors on the dynamic strength and microstructure of saline soils were analyzed $[20,21]$.

The research results on the mechanical characteristics of saline soil are mostly concentrated on static conditions. But the saline soil of the roadbed not only bears the influence of changes in external factors such as temperature, but also sustains tens of thousands of traffic loading. Therefore, UU triaxial dynamic tests were developed on chlorine saline soil with different factors, and SPSS software was used for the significance test. The effect of single factor and interaction between factors on the mechanical characteristics of chlorine saline soil was analyzed. The results provided a useful reference for the engineering construction in the area of overchlorine saline soil.

\section{Materials and Methods}

2.1. Materials of Chlorine Saline soil. The chlorine saline soil for the test was taken from a highway in the Qarhan Salt Lake area of Qinghai Province, China. The area has a typical plateau continental climate. There is little precipitation, the rain and heat are in the same season, and the precipitation varies greatly with the spatial distribution in this area. The basic physical test was measured according to Test Methods of Soils for Highway Engineering [22], the particle-size grading curve was obtained by the sieving method, and the basic physical properties are shown, respectively, in Figure 1 and Table 1. A negative liquidity index indicated that the

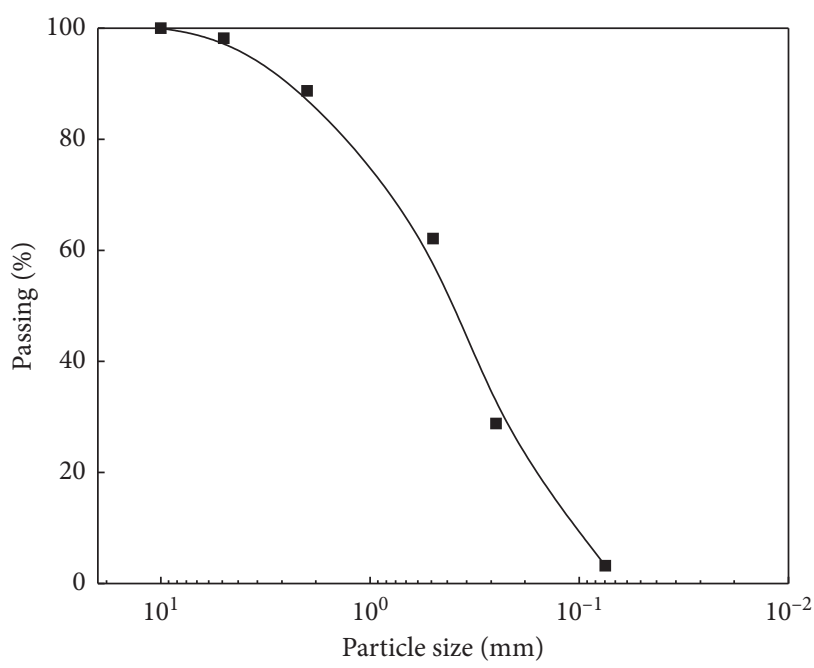

Figure 1: Particle-size curve of chlorine saline soil.

presence of crystalline salt in the soil makes the soil harder. The chemical composition analysis of chlorine saline soil was analyzed by ion chromatography, and the result is shown in Table 2. According to the Standard for Soil Test Method [23] and Specifications for Design of Highway Subgrades [24], the soil was characterized as a silty clay and over-chlorine saline soil, respectively.

2.1.1. Testing Equipment. The test was completed by a dynamic triaxial test system of Global Digital Systems, shown in Figure 2, including three modules of advanced loading, dynamic loading, and triaxial acquisition. It can realize the control of various conditions, such as different confining pressure, frequency, and wave. The test data can be collected automatically with higher test precision.

2.1.2. Sample Preparation and Testing Method. The saline soil sample needed to be dried and passed through a $2 \mathrm{~mm}$ sieve. The soil sample with the target moisture content was prepared according to the test requirements and stuffed for more than $12 \mathrm{~h}$. The reshaped triaxial samples with a compacting degree of $95 \%$, a diameter of $39.1 \mathrm{~mm}$, and a height of $80 \mathrm{~mm}$ were prepared by 5 -layer compaction with a three-part mold. The sinusoidal wave was applied to simulate traffic cyclic load through the stress control singlestage loading method, shown in Figure 3. The loading was terminated when the axial strain of the sample reaches $5 \%$ or the number of vibrations reaches 5000 [25]. Based on the analysis of the influencing factors of saline soil, the confining pressure, frequency, and moisture content were mainly considered in the test. The confining pressure was controlled at $200 \mathrm{kPa}, 300 \mathrm{kPa}$, and $400 \mathrm{kPa}$. The frequency was controlled at $0.5 \mathrm{~Hz}, 1.0 \mathrm{~Hz}$, and $2.0 \mathrm{~Hz}$. The moisture content was controlled at 3.2\%, 5.2\%, and 7.2\%. $20 \mathrm{kPa}$ was taken as a dynamic stress amplitude according to the previous study [26]. The specific test plan design is shown in Table 3. 
TABLE 1: Basic physical parameters of chlorine saline soil.

\begin{tabular}{lccccc}
\hline $\begin{array}{l}\text { Liquid limit } \\
\omega_{L}(\%)\end{array}$ & $\begin{array}{c}\text { Plastic limit } \\
\omega_{P}(\%)\end{array}$ & Plastic index IP & Liquid index $I_{L}$ & $\begin{array}{c}\text { Maximum dry density } \\
\rho_{d \max }\left(\mathrm{g} \cdot \mathrm{cm}^{-3}\right)\end{array}$ & $\begin{array}{c}\text { Optimum moisture content } \\
\omega_{\text {opt }}(\%)\end{array}$ \\
\hline 20.47 & 7.44 & 13.03 & $<0$ & 1.81 & 5.20 \\
\hline
\end{tabular}

TABLE 2: Chemical composition analysis of chlorine saline soil.

\begin{tabular}{lccrcccc}
\hline & \multicolumn{3}{c}{ Anion $(C)(\%)$} & \multicolumn{3}{c}{ Cation $(C)(\%)$} \\
\hline $\mathrm{Cl}^{-}$ & $\mathrm{SO}_{4}{ }^{2-}$ & $\mathrm{CO}_{3}{ }^{2-}$ & $\mathrm{HCO}_{3}{ }^{-}$ & $\mathrm{Na}^{+}$ & $\mathrm{K}^{+}$ & $\mathrm{Ca}^{2+}$ & $\mathrm{Mg}^{2+}$ \\
17.950 & 0.320 & 0.010 & 0.049 & 11.160 & 0.061 & 0.22 & 0.20 \\
\hline
\end{tabular}

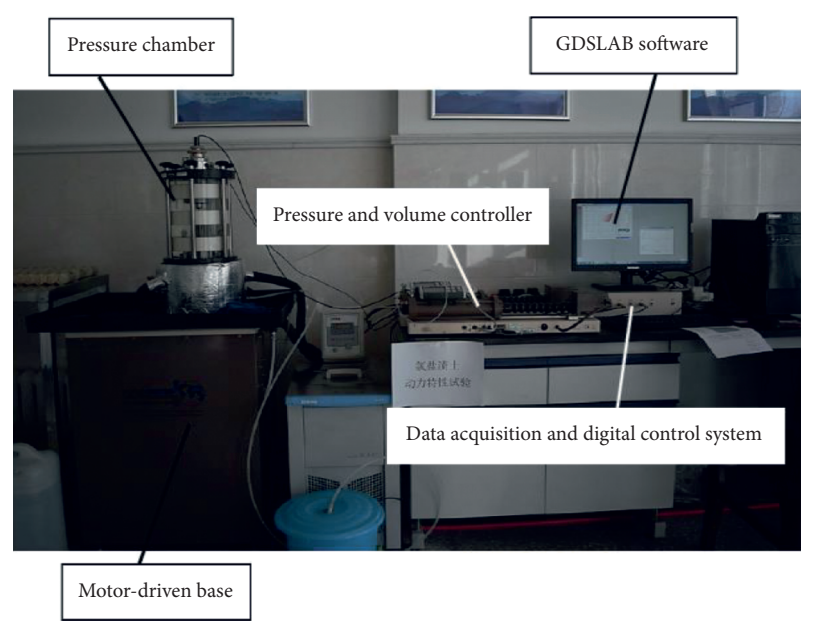

FIGURE 2: GDS dynamic triaxial test system.

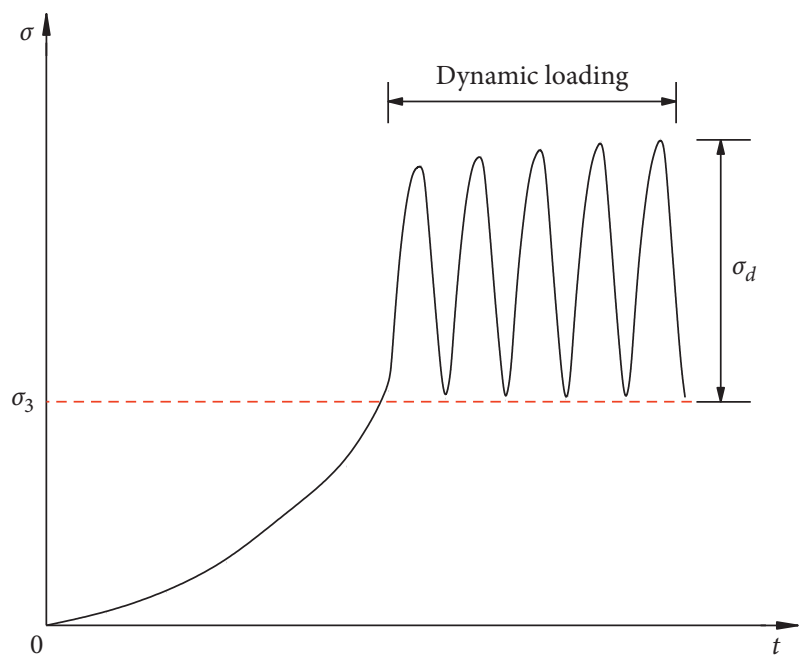

Figure 3: The curve of axial single-stage loading.

TABLE 3: Test plan design.

\begin{tabular}{lcc}
\hline Confining pressure $(\mathrm{kPa})$ & Moisture content $(\%)$ & Frequency $(\mathrm{Hz})$ \\
\hline 200 & 3.2 & 0.5 \\
300 & 5.2 & 1.0 \\
400 & 7.2 & 2.0 \\
\hline
\end{tabular}

2.1.3. Principle of Significance Test considering the Interaction between Factors. For saline soils with high salinity, the analysis of mechanical characteristics should not only take into account the particularity of the soil itself, but also the effect of moisture content, frequency, confining pressure, and other factors. In addition, the interaction between multiple factors should not be completely ignored. If there is no interaction between the influencing factors, the effect of a single factor can be studied separately and then superimposed. But if the interaction between multiple factors is obvious, the comprehensive effect of the interaction should be considered. The significance test can be used to study the influence of different factors on the mechanical characteristics of high-salinity soil. In other words, the $F$ test is performed on mechanical parameters under a certain degree of confidence, so as to judge whether single-factor and multifactor interaction have a greater effect on mechanical characteristics in the test [27].

For the three factors $A, B$, and $C$, there are $m, n$, and $r$ levels of each factor, respectively. An experiment is performed at each combined level $\left(A_{\mathrm{i}}, B_{\mathrm{j}}\right.$, and $\left.C_{\mathrm{k}}\right)$; the observed value of the test index can be obtained as $x_{i j k}$. The computational method of symbols is expressed in the following equations:

$$
\begin{aligned}
R & =\sum_{i=}^{m} \sum_{j=1}^{n} \sum_{k=1}^{r} x_{i j k}^{2}, \\
C T & =\frac{1}{m n r}\left(\sum_{i=}^{m} \sum_{j=1}^{n} \sum_{k=1}^{r} x_{i j k}\right)^{2}, \\
Q_{A} & =\frac{1}{n r} \sum_{i=1}^{m}\left(\sum_{j=1}^{n} \sum_{k=1}^{r} x_{i j k}\right)^{2}, \\
Q_{B} & =\frac{1}{m r} \sum_{j=1}^{n}\left(\sum_{i=1}^{m} \sum_{k=1}^{r} x_{i j k}\right)^{2}, \\
Q_{C} & =\frac{1}{m n} \sum_{k=1}^{r}\left(\sum_{i=1}^{m} \sum_{j=1}^{n} x_{i j k}\right)^{2} .
\end{aligned}
$$

The sum of squares of the total variance is obtained by the following equation:

$$
S_{T}=Q_{T}-C T \text {. }
$$

The sum of squares of the variance of factors $A, B$, and $C$ and error $E$ are, respectively, calculated by the following equations: 


$$
\begin{aligned}
& S_{A}=Q_{A}-C T, \\
& S_{B}=Q_{B}-C T, \\
& S_{C}=Q_{C}-C T, \\
& S_{E}=S_{T}-S_{A}-S_{B} .
\end{aligned}
$$

The estimated variances $F_{A}, F_{B}$, and $F_{C}$ of factors $A, B$, and $C$ can be, respectively, expressed as follows:

$$
\begin{gathered}
F_{A}=\frac{S_{A} / f_{A}}{S_{E} / f_{E}}, \\
F_{B}=\frac{S_{B} / f_{B}}{S_{E} / f_{E}}, \\
F_{C}=\frac{S_{C} / f_{C}}{S_{E} / f_{E}},
\end{gathered}
$$

where $f_{A}, f_{B}, f_{C}$, and $f_{E}$ are, respectively, the degree of freedom of factors $A, B$, and $C$ and error $E$. For a significant level $\alpha$, if $F_{A} \geq F_{\alpha}\left(f_{A}, f_{\alpha}\right)$, then it can be seen that the effect of factor $A$ on the index is significant; otherwise, it is not significant. The same method can be used to judge the significance of factors $B$ and $C$.

As for the significant study of three factors, the interaction between $A \times B \times C$ is generally weak, so it is not considered in practice, and only the interaction between two factors is considered. Then, the computational method is denoted by the following equations:

$$
\begin{gathered}
Q_{A B}=\frac{1}{r} \sum_{i=1}^{m} \sum_{j=1}^{n}\left(\sum_{k=1}^{r} x_{i j k}\right)^{2}, \\
Q_{A C}=\frac{1}{n} \sum_{i=1}^{m} \sum_{k=1}^{r}\left(\sum_{j=1}^{n} x_{i j k}\right)^{2}, \\
Q_{B C}=\frac{1}{m} \sum_{j=1}^{n} \sum_{k=1}^{r}\left(\sum_{i=1}^{m} x_{i j k}\right)^{2} .
\end{gathered}
$$

Further, the sum of squares of the variance of interaction effect of factors $A$ and $B$, factors $A$ and $C$, and factors $B$ and $C$ can be indicated by the following equations:

$$
\begin{aligned}
& S_{A B}=Q_{A B}-Q_{A}-Q_{B}+C T, \\
& S_{A C}=Q_{A C}-Q_{A}-Q_{C}+C T, \\
& S_{B C}=Q_{B C}-Q_{B}-Q_{C}+C T,
\end{aligned}
$$

And the significance analysis method of the interaction between factors is the same as that of single-factor analysis.

$F_{\alpha}\left(f_{1}, f_{2}\right)$ was the critical value of $F$ test, shown in Table 4 . The evaluation of the significant effect was specified as follows: if $\alpha<0.001$, its significance is I; if $0.001 \leq \alpha<0.01$, its
TABLe 4: $F$ test critical values $F_{\alpha}\left(f_{1}, f_{2}\right)$.

\begin{tabular}{lcccccc}
\hline Significant level $\alpha$ & 0.1 & 0.05 & 0.025 & 0.01 & 0.005 & 0.001 \\
\hline$f_{1}=2, f_{2}=4$ & 4.32 & 6.94 & 10.65 & 18.00 & 26.28 & 61.25 \\
$f_{1}=2, f_{2}=8$ & 3.11 & 4.46 & 6.06 & 8.65 & 11.04 & 18.49 \\
$f_{1}=4, f_{2}=8$ & 2.81 & 3.84 & 5.05 & 7.01 & 8.81 & 14.39 \\
\hline
\end{tabular}

significance is II; if $0.01 \leq \alpha<0.1$, its significance is III; and if $\alpha \geq 0.1$, its significance is IV.

\section{Results and Discussion}

3.1. Dynamic Stress-Strain Curves. The maximum dynamic stress and maximum dynamic strain (the vertices of each stress-strain hysteresis loop, Figure 4) could be drawn under different dynamic stress cycles to obtain the dynamic stress-strain backbone curve (Figure 5), which was adequate evidence that the curves performed a strain-hardening behaviour for all samples [28].

The effects of different confining pressures, moisture content, and frequency on stress-strain curves were compared and analyzed. As shown in Figure 5(a) and 5(b), it was evident that the dynamic stress increased with the increase of confining pressure and frequency under the same other conditions. But the failure strength was the maximum at the best moisture content under the same confining pressure and frequency.

The hyperbolic model of equation (7) used to fit the dynamic stress-strain curve was proposed by Konder as early as 1963 [29]. After analysis and fitting, it is found that the dynamic stress-strain curves of chlorine saline soil with high salinity under dynamic load were difficult to be described by equation (7). Therefore, equation (8) [30] was used to fit the dynamic stress-strain curves:

$$
\begin{gathered}
\sigma_{d}=\frac{\varepsilon_{d}}{a+b \varepsilon_{d}}, \\
\sigma_{d}=\frac{a \varepsilon_{d}^{b}}{1+c \varepsilon_{d}^{b}},
\end{gathered}
$$

where $\sigma_{d}$ and $\varepsilon_{d}$ are dynamic stress and dynamic strain and $a$, $b$, and $c$ are parameters related to the test conditions and the physical properties of the soil.

Furthermore, equation (9) was obtained from the special conditions using $\varepsilon_{d} \longrightarrow+\infty$ in equation (8) as follows:

$$
\sigma_{d \max }=\left.\sigma_{d}\right|_{\varepsilon_{d}} \longrightarrow+\infty=\frac{a}{c}
$$

The results of the related fitting parameters in the experiment were $a, b, c$, and $\sigma_{d \max }$, as shown in Table 5 .

According to the different types of dynamic stress-strain curves, the principles for determining the failure strength of soil are also different. From the achieved stress-strain curves, the average value of the dynamic stress after the stress-strain curve stabilizes is taken as the failure strength.

The change curves of failure strength under different influencing factors obtained from the test results were shown in Figure 6. The effects of different confining pressures, 


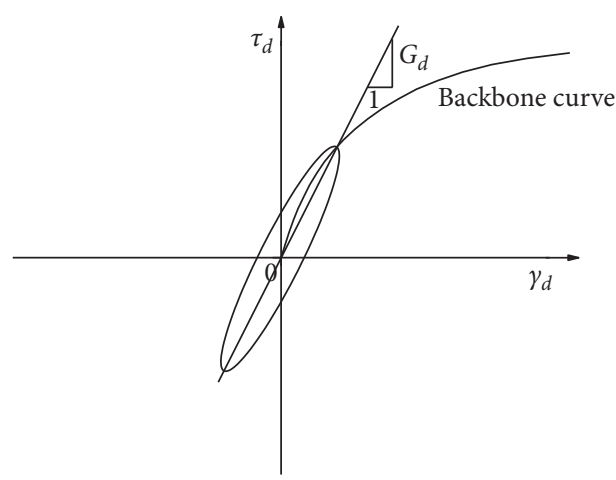

FIgURE 4: Hysteresis curve and backbone curve.

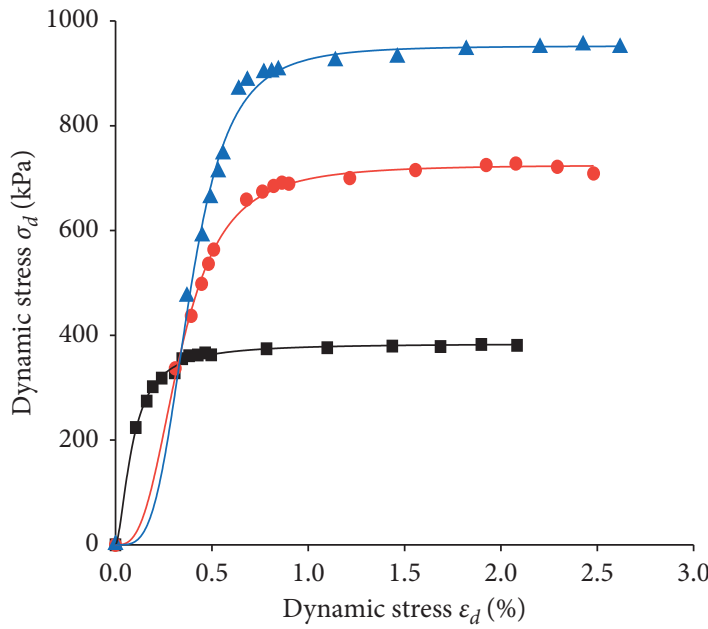

- $\sigma_{3}=200 \mathrm{kPa}$

- $\sigma_{3}=300 \mathrm{kPa}$

$\Delta \sigma_{3}=400 \mathrm{kPa}$

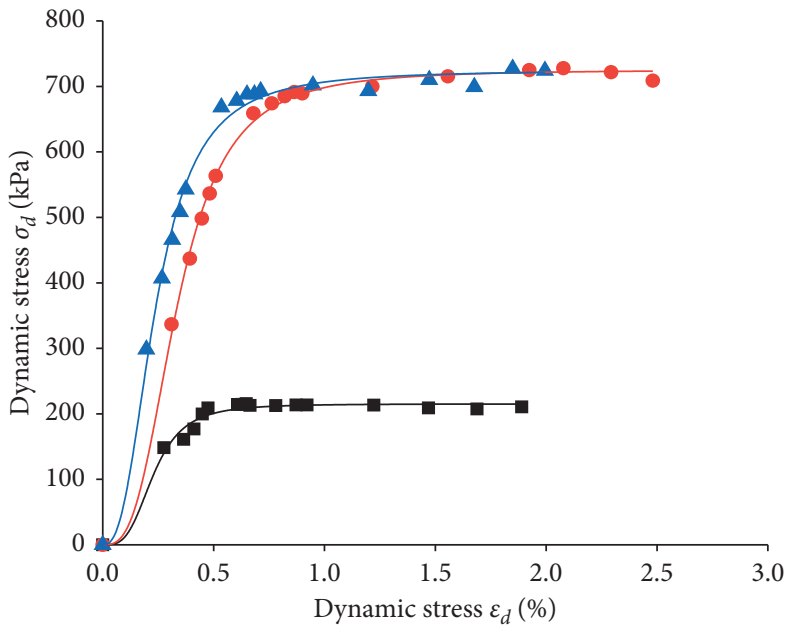

- $f=0.5 \mathrm{~Hz}$

- $f=1.0 \mathrm{~Hz}$

A $f=2.0 \mathrm{~Hz}$

(a)

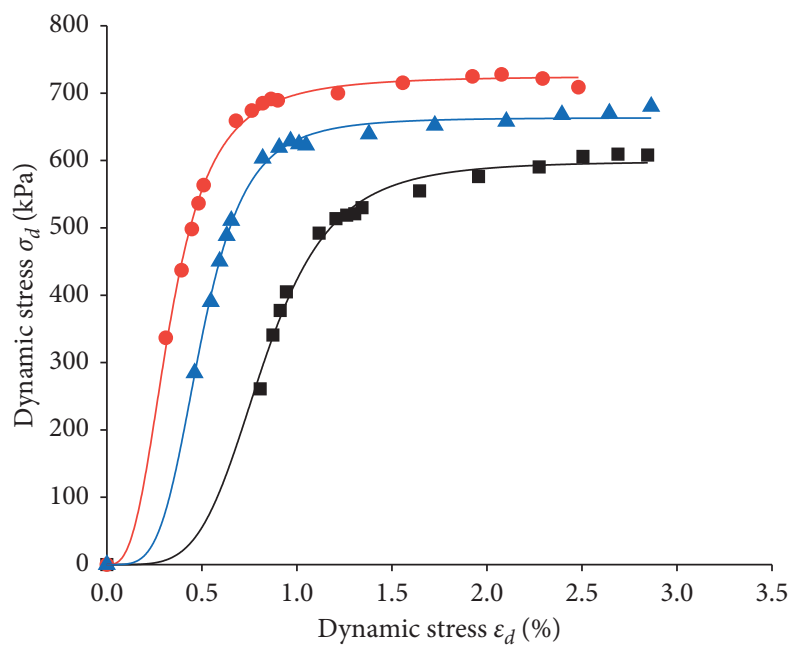

- $\omega=3.20 \%$

- $\omega=5.20 \%$

$\Delta \omega=7.20 \%$ $-\omega=3.20 \%$ fitting curves

$\omega=5.20 \%$ fitting curves

$\omega=7.20 \%$ fitting curves

(c)

Figure 5: Dynamic stress-dynamic strain relationship curves. (a) $f=1.0 \mathrm{~Hz}, \omega=5.20 \%$, (b) $\omega=5.20 \%, \sigma_{3}=300 \mathrm{kPa}$, and (c) $f=1.0 \mathrm{~Hz}$, $\sigma_{3}=300 \mathrm{kPa}$. 
TABLE 5: Chlorine saline soil test conditions and the fitting values of backbone curve parameters.

\begin{tabular}{lcccccccc}
\hline Test group & $\sigma_{3}(\mathrm{MPa})$ & $f(\mathrm{~Hz})$ & $\omega(\%)$ & $a$ & $b$ & $c$ & $\sigma_{d \max }(\mathrm{MPa})$ & $R^{2}$ \\
\hline \multirow{3}{*}{ BYZ1 } & 0.2 & 1.0 & 5.2 & 20786.65 & 1.65 & 54.07 & 0.38 & 0.997 \\
& 0.3 & & & 18695.38 & 2.97 & 25.78 & 0.73 & 0.997 \\
& 0.4 & & & 34231.06 & 3.75 & 35.95 & 0.95 & 0.992 \\
\hline \multirow{3}{*}{ BYZ2 } & 0.3 & 0.5 & 5.2 & 30981.62 & 3.38 & 143.98 & 0.22 & 0.977 \\
& & 1.0 & & 18695.38 & 2.97 & 25.78 & 0.73 & 0.998 \\
& & 2.0 & & 28604.87 & 2.57 & 39.48 & 0.72 & 0.994 \\
BYZ3 & 0.3 & 1.0 & 3.2 & 1441.33 & 4.57 & 2.41 & 0.60 & 0.993 \\
& & & 5.2 & 18695.38 & 2.97 & 25.78 & 0.73 & 0.998 \\
& & & 7.2 & 12695.06 & 4.21 & 19.13 & 0.997 \\
\hline
\end{tabular}

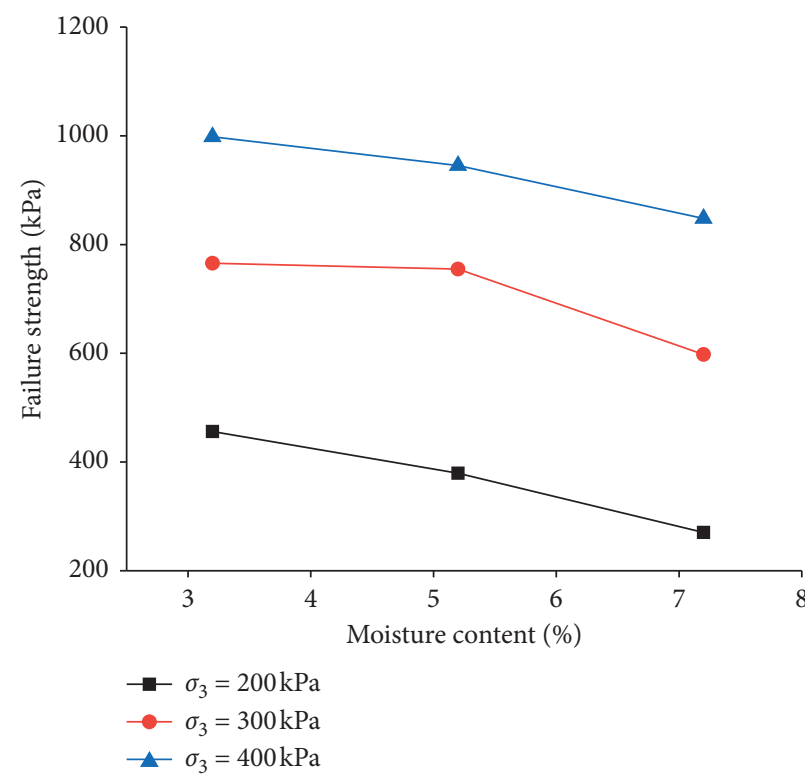

(a)

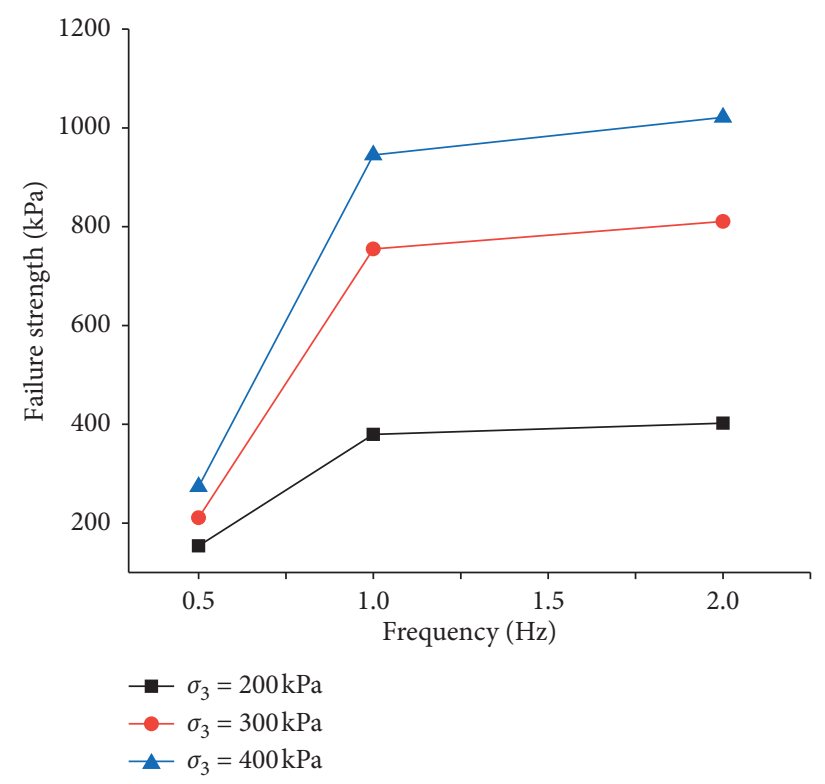

(b)

FIGURE 6: Variety regularity of failure strength with moisture content and frequency. (a) $f=1.0 \mathrm{~Hz}$. (b) $\omega=5.20 \%$.

moisture content, and frequency on the failure strength were compared and discussed.

As shown in Figure 6, it was evident that the failure strength of chlorine saline soil increased significantly with the increase of confining pressures. Under higher confining pressure, the porosity of the soil decreased. Soil particles were filled with each other to form a tighter framework structure, the friction and uneven occlusion between soil particles were enhanced, and the ability to resist external deformation heightens. Therefore, the failure strength increased with the increase of confining pressure.

Figure 6(a) showed the failure strength of chlorine saline soil decreases gradually with the increase of moisture content. Under the condition of certain salinity, with the increase of moisture content, on one hand, the presence of pore water weakened the interaction between particles. On the other hand, it also reduced the bonding force between soil particles and leads to the decrease of soil strength. Therefore, the failure strength decreased with the increase of moisture content.

Figure 6(b) showed that the failure strength of chlorine saline soil increases with the increase of frequency. The frequency changed from $0.5 \mathrm{~Hz}$ to $1.0 \mathrm{~Hz}$, and the failure strength changed notably. The frequency indirectly reflected the speed of driving. The smaller the frequency, the longer the cyclic loading acts on the soil, and the greater the effect on the soil. On the contrary, the frequency had a smaller effect on the bite force and bonding force between soil particles. The soil still had a stronger ability to resist deformation, and the failure strength increased with the increase of frequency.

Taking confining pressure, moisture content, and frequency, respectively, as factors $A, B$, and $C$, there were 3 levels of each factor. The significance of the failure strength under the interaction between factors was studied, and the computational results were shown in Table 6.

According to the significant levels given in Table 4, the effect of confining pressure and frequency on the failure strength was significant while the effect of moisture content was not significant. In addition, the interaction between confining pressure and frequency had a significant effect on the failure strength of chlorine saline soil. The interaction between confining pressure and moisture content and that between frequency and moisture content were significant 
TABLE 6: Significance test of failure strength considering interactions.

\begin{tabular}{lcccc}
\hline Source of variance & Sum of squares & Degree of freedom & $F$ value & Significance \\
\hline Confining pressure $A$ & 682595.48 & 2 & 133.48 & I \\
Moisture content $B$ & 367.00 & 2 & 2 & 259.71 \\
Frequency $C$ & 1328069.8 & 4 & 1.88 & IV \\
$A \times B$ & 19176.49 & 4 & 16.23 & I \\
$A \times C$ & 165960.64 & 4 & 2.07 & IV \\
$B \times C$ & 21128.29 & 8 & I \\
\hline Errors & 20454.99 & 26 & \\
Sums & 2237752.70 & & \\
\hline
\end{tabular}

when the significant level $\alpha$ was greater than or equal to 0.100. It was clear from Table 6 that the significance of the effect of each single factor and the interaction between multiple factors on the failure strength was frequency $C$, confining pressure $A, A \times C, B \times C, A \times B$, and moisture content $B$ in order.

3.1.1. Effects of the Different Factor on the Dynamic Elastic Modulus. The elastic modulus is a key parameter to describe the properties of soil, and it also plays an important role in deformation and stability analysis in geotechnical engineering; then, it is usually acquired in smaller strain. The computational methods of static elastic modulus and dynamic elastic modulus are different. Lee et al. [31] took the ratio of the deviant stress increment corresponding to $1.5 \%$ of strain to the axial strain increment as the static elastic modulus of soil, and Wang [32] choose the tangent modulus as the static elastic modulus of soil. However, the computational method of dynamic elastic modulus is as shown in equation (10a):

$$
\begin{aligned}
& E_{d}=\frac{\sigma_{d}}{\varepsilon_{d}}, \\
& \sigma_{d}=\frac{\left(\sigma_{d \max }-\sigma_{d \min }\right)}{2}, \\
& \varepsilon_{d}=\frac{\left(\varepsilon_{d \max }-\varepsilon_{d \min }\right)}{2},
\end{aligned}
$$

where $E_{d}$ is dynamic elastic modulus, $\sigma_{d}$ and $\varepsilon_{d}$ are, respectively, axial dynamic stress and axial dynamic strain; the computational method is as shown in equations (10b) and (10c).

Figure 7 shows the dynamic elastic modulus changes of chlorine saline soil with different moisture content, frequency, and confining pressure. It could be seen that dynamic elastic modulus was increasing with confining pressure. In addition, the dynamic elastic modulus increased at the beginning and then decreased with the increase of moisture content, but there was an exception when the confining pressure was $200 \mathrm{kPa}$, which was considered to be caused by the test error. However, the change of dynamic elastic modulus with frequency was not explicit.

Table 7 shows the significance analysis results of the effect of confining pressure, moisture content, and frequency on dynamic elastic modulus. According to the significant levels given in Table 4, the effect of confining pressure and frequency on dynamic elastic modulus was significant. Furthermore, the effect of moisture content and the interaction between confining pressure and moisture content was significant when significant level $\alpha$ was larger than or equal to 0.005 ; the effect of the interaction between confining pressure and moisture content and the interaction between confining pressure and frequency were significant when significant level $\alpha$ was greater than or equal to 0.01 . As could be seen from Table 5, the significance of the effect of each single factor and the interaction between multiple factors on dynamic elastic modulus followed the order of confining pressure $A$, frequency $C$, moisture content $B$, and confining pressure $A, B \times C, A \times C$, and $A \times B$ (from greatest to least).

\subsubsection{Effect of Different Factors on Shear Strength} Parameters. The properties of soil are extremely complex, so the strength of soil should not be simply considered as the strength of mineral particles, but the interaction effect between particles must be considered. Similarly, the shear strength of soil also depends on many factors, which are generally divided into two categories. One is the properties of the soil itself, such as physical properties; the other is the external conditions of the soil, such as stress and strain conditions. In the practical application, the most common theory of shear strength is the Mohr-Coulomb strength criterion with only two parameters: cohesion $c$ and friction angle $\varphi$.

The cohesion is mainly provided by physical and chemical forces such as electrostatic force and Van der Waals' force and is affected by ion concentration, ion valence, and the mineral composition of particles. The friction angle can reflect the mutual movement and bite between particles, such as friction caused by sliding between particles.

According to the results of the unconsolidated undrained triaxial test, take $\left(\sigma_{1}+\sigma_{3}\right) / 2$ and $\left(\sigma_{1}-\sigma_{3}\right) / 2$ as the center of the circle and the radius, draw the stress circle under different test conditions and the common tangent of the circle, and obtain the inclination angle and longitudinal intercept from the strength envelope, that is, to obtain the required dynamic cohesion $c_{d}$ and dynamic friction angle $\varphi_{d}$.

Figure 8 shows the relationship between dynamic friction angle and dynamic cohesion with the moisture content of chlorine saline soil under different loading frequencies. It could be seen that the dynamic cohesion and dynamic friction angle decrease with the increase of moisture content. 


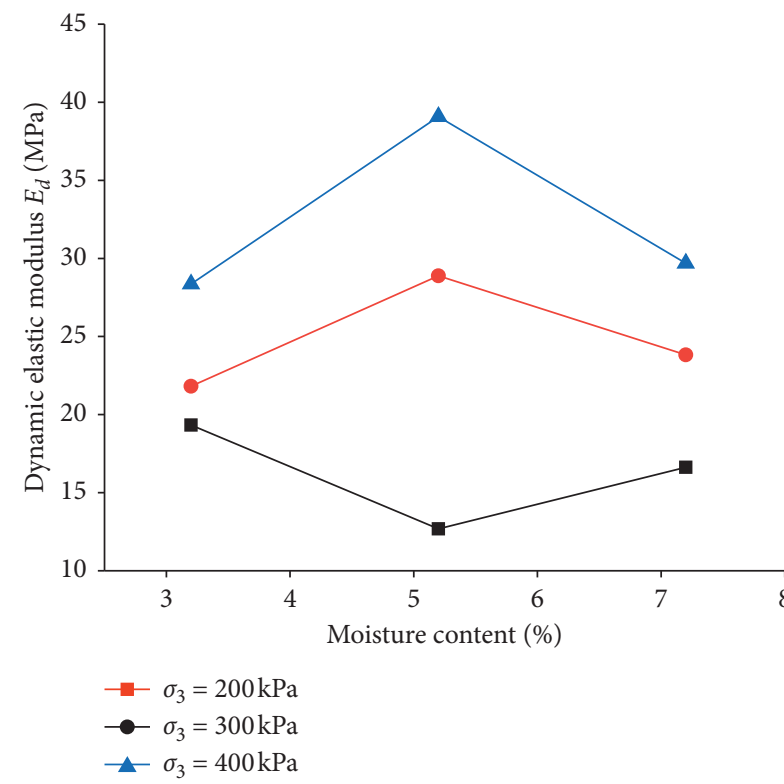

(a)

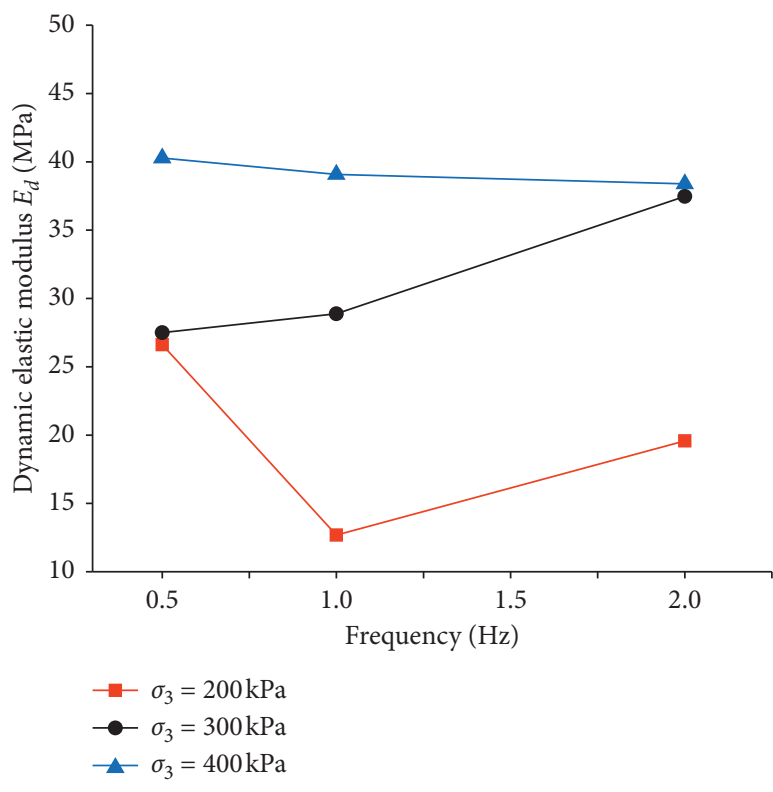

(b)

FigURE 7: Variety regularity of dynamic elastic modulus with moisture content and frequency. (a) $(f)=1.0 \mathrm{~Hz}$. (b) $\omega=5.20 \%$.

TABLe 7: Significance test of dynamic elastic modulus.

\begin{tabular}{|c|c|c|c|c|}
\hline Source of variance & Sum of squares & Degree of freedom & $F$ value & Significance \\
\hline Confining pressure $A$ & 1852.77 & 2 & 36.38 & I \\
\hline Moisture content $B$ & 371.96 & 2 & 10.95 & II \\
\hline Frequency $C$ & 1123.09 & 2 & 33.08 & $\mathrm{I}$ \\
\hline$A \times B$ & 201.41 & 4 & 2.97 & III \\
\hline$A \times C$ & 302.18 & 4 & 4.45 & III \\
\hline$B \times C$ & 657.07 & 4 & 9.68 & II \\
\hline Errors & 118.85 & 8 & & \\
\hline Sums & 3855.02 & 26 & & \\
\hline
\end{tabular}

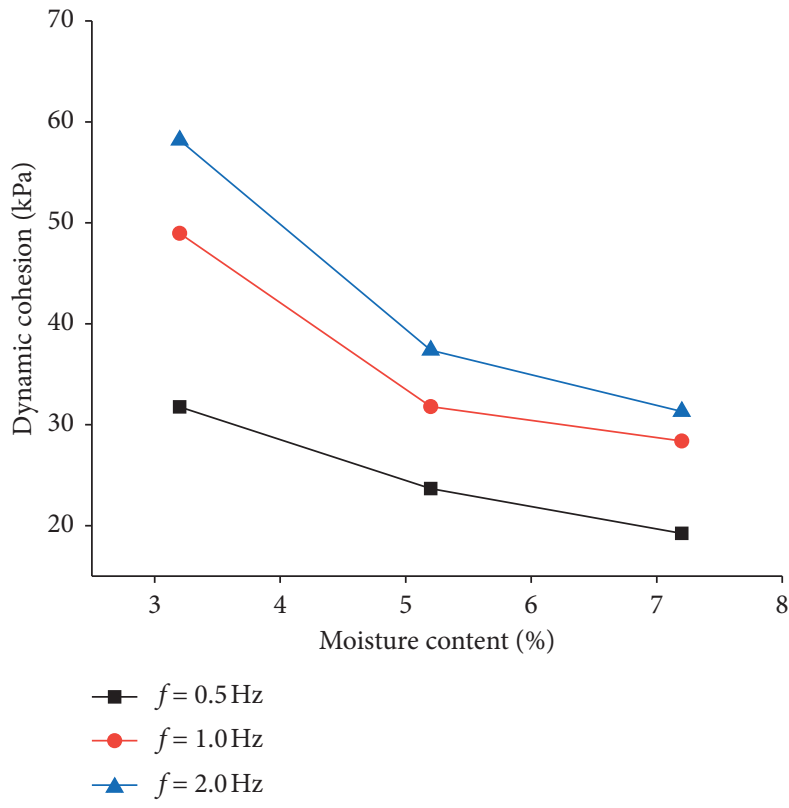

(a)

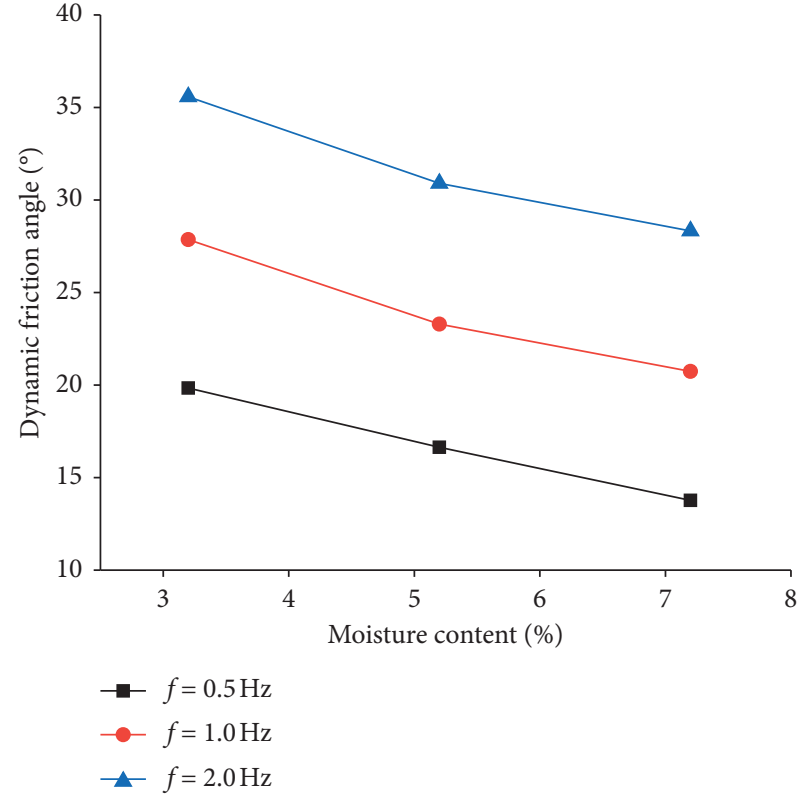

(b)

FIGURE 8: Variety regularity of shear strength parameter with water content and frequency. (a) Dynamic cohesion. (b) Dynamic friction angle. 
TABLE 8: Significant test of cohesion of influencing factors.

\begin{tabular}{lcccc}
\hline Source of variance & Sum of squares & Degree of freedom & $F$ value & Significance \\
\hline Moisture content $B$ & 887.44 & 2 & 4.10 & IV \\
Frequency $C$ & 701.97 & 2 & & 3.24 \\
\hline Errors & 432.83 & 4 & \\
Sums & 2022.23 & 8 & \\
\hline
\end{tabular}

Table 9: Significant test of the friction angle of influencing factors.

\begin{tabular}{lcccc}
\hline Source of variance & Sum of squares & Degree of freedom & $F$ value & Significance \\
\hline Moisture content $B$ & 87.85 & 2 & 2.00 & IV \\
Frequency $C$ & 623.97 & 2 & I \\
\hline Errors & 87.83 & 8 & \\
Sums & 799.65 & 8 & \\
\hline
\end{tabular}

When the frequency was $1.0 \mathrm{~Hz}$, the dynamic cohesion decreased dramatically from $48.96 \mathrm{kPa}$ to $31.80 \mathrm{kPa}$ and the dynamic friction angle decreased quickly from $27.86^{\circ}$ to $20.74^{\circ}$ as moisture content increased from $3.2 \%$ to $5.2 \%$. So, the dynamic cohesion and dynamic friction angle increased with the increase of frequency. When the moisture content was $5.2 \%$, the dynamic cohesion increased rapidly from $23.66 \mathrm{kPa}$ to $31.80 \mathrm{kPa}$ and the dynamic friction angle increased obviously from $16.64^{\circ}$ to $23.29^{\circ}$ as frequency increased from $0.5 \mathrm{~Hz}$ to $1.0 \mathrm{~Hz}$. In summary, the higher the loading frequency and the lower the moisture content might be obtained, the larger the dynamic cohesion and dynamic friction angle.

With the increase of moisture content, the pore water filled between soil particles would increase, the electrostatic attraction, Van der Waals' force and the ion concentration in the soil would decrease, and the electrokinetic potential of the colloid in the soil would increase, resulting in the enhancement of the mutual interaction between the colloids. And the thickness of hydration film on the surface of soil particles increased with the increasing of moisture content. Besides, the salt solution acted as a lubricant in the soil and weakened the bonding force between soil particles. Therefore, the dynamic friction angle and dynamic cohesion of chlorine saline soil decrease with the increase of moisture content, and shear strength also decreased. If loading frequency was too high, the effect of cyclic loading would be inadequate on the soil, and it would have little effect on the biting force and bonding force between soil particles. The soil could resist external deformation. Therefore, the shear strength increased with the increase of loading frequency.

The significance analysis results of the effect of moisture content and frequency on the dynamic cohesion and dynamic friction angle of chlorine saline soil are indicated in Tables 8 and 9, respectively.

According to the significance test level given in Table 4, it could be judged that the effect of frequency on dynamic cohesion and dynamic friction angle was significant, while the effect of moisture content was not significant.

Based on the above analysis, it could be seen that not only single factors such as confining pressure, moisture content, and frequency had a certain effect on the mechanical characteristics of chlorine saline soil, but also the effect of the interaction of multiple factors might be significant. Therefore, it was necessary to consider the effect of a single factor and the interaction between multiple factors on the mechanical characteristics of soil comprehensively, instead of analyzing the independent influence of each single factor only.

\section{Conclusions}

The mechanical characteristics of chlorine saline soil affected by a number of factors were studied, and the following conclusions have been drawn:

(1) The dynamic stress-dynamic strain curve of chlorine saline soil was strain-hardening. Although the hyperbolic model was not well fitted, the power function model achieved a quite good fit of over $97 \%$.

(2) The confining pressure, frequency, and the interaction between confining pressure and frequency could significantly affect the failure strength and dynamic elastic modulus. Some discrepancies in the changes of the failure strength and dynamic elastic modulus with factors were observed.

(3) The effect of frequency on dynamic cohesion and dynamic friction angle was more significant, which increased with the increase of frequency. While moisture content had a weaker effect, dynamic cohesion and dynamic friction angle decreased as moisture content increased.

(4) Based on the significance test theory, the effect of confining pressure and frequency on the mechanical properties of chlorine saline soil was significant, but the effect of moisture content was weaker. It could be obtained that the effect of interaction between confining pressure and frequency was significant simultaneously. Therefore, when studying the mechanical characteristics of soil, the interaction between multiple factors needs to be taken into consideration. 


\section{Data Availability}

The data used in the paper have been uploaded on the Baidu Netdisk (https://pan.baidu.com/s/1Xjw1k7QZ9LbYq6znsGZ4aQ); extract code: $0 i 96$. These data are automatically collected by GDS.

\section{Conflicts of Interest}

The authors declare that they have no conflicts of interest regarding the publication of this paper.

\section{Acknowledgments}

This research was supported by the National Natural Science Foundation (NSFC) under Grant no. 41471052 and the Science and Technology Department Project of Qinghai Province under Grant no. 2021-ZJ-908.

\section{References}

[1] J. S. Yang, "Development and prospect of the research on saltaffected soils in China," Acta Pedol Sin, vol. 45, no. 5, pp. 837-845, 2008.

[2] Z. Q. Wang, S. Q. Zhu, and R. P. Yu, Chinese Saline Soils, Science Press, Beijing, China, 1993.

[3] H. J. Wang and Y. Y. Zhao, "Engineering geological characteristics of superchlorinated saline soil," Hydrogeology and Engineering Geology, vol. 1, pp. 39-40, 1981.

[4] X. S. Yang, J. Q. Dang, and L. L. Wang, "Experimental research on the shear strength characteristics of saturated chlorine saline soil," Geotechnical Investigation \& Surveying, vol. 232, no. 11, pp. 6-9, 2008.

[5] J. Fang, X. Li, J. Liu, C. Liu, Z. Liu, and Y. Ji, "The crystallization and salt expansion characteristics of a silty clay," Cold Regions Science and Technology, vol. 154, no. 10, pp. 63-73, 2018.

[6] Y. Zhang, Z. Yang, J. Liu, and J. Fang, "Impact of cooling on shear strength of high salinity soils," Cold Regions Science and Technology, vol. 141, no. 6, pp. 122-130, 2017.

[7] H. Bing and P. He, "Influence of freeze-thaw cycles on physical and mechanical properties of salty soil," Chinese Journal of Geotechnical Engineering, vol. 31, no. 12, pp. 1958-1962, 2009.

[8] Y. Han, Q. Wang, N. Wang et al., "Effect of freeze-thaw cycles on shear strength of saline soil," Cold Regions Science and Technology, vol. 154, no. 2, pp. 42-53, 2018.

[9] M. Li, S. Chai, H. Du, and C. Wang, "Effect of chlorine salt on the physical and mechanical properties of inshore saline soil treated with lime," Soils and Foundations, vol. 56, no. 3, pp. 327-335, 2016.

[10] Y. Liu, Q. Wang, S. Liu et al., "Experimental investigation of the geotechnical properties and microstructure of lime-stabilized saline soils under freeze-thaw cycling," Cold Regions Science and Technology, vol. 161, no. 3, pp. 32-42, 2019.

[11] W. Zhang, J. Ma, and L. Tang, "Experimental study on shear strength characteristics of sulfate saline soil in Ningxia region under long-term freeze-thaw cycles," Cold Regions Science and Technology, vol. 160, no. 8, pp. 48-57, 2019.

[12] X. S. Yang, J. Q. Liu, and J. Q. Dang, "Experimental research on the engineering property of chlorine saline soil improved by fly ash," Chinese Journal of Geotechnical Engineering, vol. 29, no. 11, pp. 82-86, 2012.
[13] Z. Y. Zhang, Y. C. J. Luo, and X. J. Pei, "Engineering characteristic of reinforcement chlorine saline soil in Coastal," Journal of Civil Engineering and Management, vol. 34, no. 04, pp. 59-63, 2017.

[14] Y. Lai, X. Wan, and M. Zhang, "An experimental study on the influence of cooling rates on salt expansion in sodium sulfate soils," Cold Regions Science and Technology, vol. 124, pp. 67-76, 2016.

[15] Y. Lai, D. Wu, and M. Zhang, "Crystallization deformation of a saline soil during freezing and thawing processes," Applied Thermal Engineering, vol. 120, pp. 463-473, 2017.

[16] S. Zhang, X. Yang, S. Xie, and P. Yin, "Experimental study on improving the engineering properties of coarse grain sulphate saline soils with inorganic materials," Cold Regions Science and Technology, vol. 170, Article ID 102909, 2020.

[17] O. S. B. Al-Amoudi and S. N. Abduljauwad, "Compressibility and collapse characteristics of arid saline sabkha soils," Engineering Geology, vol. 39, no. 3-4, pp. 185-202, 1995.

[18] P. N. Mishra, A. Scheuermann, T. Bore et al., "Salinity effects on soil shrinkage characteristic curves of fine-grained geomaterials," Journal of Rock Mechanics and Geotechnical Engineering, vol. 11, no. 01, pp. 185-195, 2018.

[19] Y. Zhao, Y. Lai, J. Zhang, and M. Liao, "A dynamic strength criterion for frozen sulfate saline silty clay under cyclic loading," Cold Regions Science and Technology, vol. 173, Article ID 103026, 2020.

[20] F. T. Zhao, L. J. Chang, and W. Y. Zhang, "Experimental study on dynamic strength characteristics of frozen saline soil under stepped cyclic loading," Journal of Glaciology and Geocryology, vol. 41, no. 06, pp. 1397-1405, 2019.

[21] F. T. Zhao, L. J. Chang, and W. Y. Zhang, "Analysis on the influence of cyclic stress ratio and vibration frequency on microstructure of saline soil," Journal of Glaciology and Geocryology, vol. 42, no. 03, pp. 854-864, 2020.

[22] JTG E40-2007, Test Methods of Soils for Highway Engineering, China Communications Press, Beijing, China, 2007.

[23] GB/T 50123-2019, Standard for Soil Test Method, China Planning Press, Beijing, China, 2019.

[24] JTG D30-2015, Specifications for Design of Highway Subgrades, China Communications Press Co., Ltd., Beijing, China, 2015.

[25] D. Y. Xie, Soil Dynamics, Higher Education Press, Beijing, China, 2011.

[26] Z. F. Huang, Experimental Study on Properties of Traffic Silt Embankment under Cyclic Dynamic Loading, Tianjin University, Tianjin, China, 2011.

[27] S. Q. Li, L. X. Gao, and S. X. Chai, "Significance and interaction of factors on mechanical properties of frozen soil," Rock Soil Mechanics, vol. 33, no. 4, pp. 1173-1177, 2012.

[28] J. Liu, D. Chang, and Q. Yu, "Influence of freeze-thaw cycles on mechanical properties of a silty sand," Engineering Geology, vol. 210, pp. 23-32, 2016.

[29] G. X. Li, Advanced Soil Mechanics, Tsinghua University Press, Beijing, China, Second edition, 2016.

[30] Y. Zhang, L. W. Kong, A. G. Guo et al., "Cumulative plastic strain of saturated soft clay under cyclic loading," Rock Soil Mechanics, vol. 30, no. 06, pp. 1542-1548, 2009.

[31] W. Lee, N. C. Bohra, A. G. Altschaeffl, and T. D. White, "Resilient modulus of cohesive soils and the effect of freezethaw," Canadian Geotechnical Journal, vol. 32, no. 4, pp. 559-568, 1995.

[32] J. Wang, Research on the Mechanical Properties of Subgrade Soil after Several Freeze Thaw Cycles in Seasonally Frozen Soil Region and Microscopic Mechanism Analysis, Jilin University, Changchun, China, 2012. 